\title{
9. On the perception of safety in low income neighbourhoods: using digital images in a stated choice experiment
}

\section{Paula Iglesias, Margarita Greene and Juan de Dios Ortúzar}

\section{SAFETY AND URBAN SPACE}

The relationship between the environment and human behaviour has been studied in certain depth. We are now fully aware that the configuration of urban space affects individual actions. For this reason, modern definitions of urbanism include not only a responsibility for the physical aspect of the city configuration but also for the potential interaction between physical space and the human activity supported by it.

However, although it has long been recognized that the occurrence of crime is not indifferent to the characteristics of the space where it occurs, space management actions have become popular only recently. Their general aim is to reap the benefits of the inhibitory effects of certain sociospatial configurations. Unfortunately, such lines of action have lacked hard data to support them. On the other hand, rather than the actual level of risk faced in a certain situation, it is the subjective assessment of such risk that affects the daily quality of life of citizens (Paz Ciudadana, 2003), and quantifying such effects is not an easy task.

Two important research lines have managed to highlight the importance of urban space design in the prevention of crime; they have also identified and, to some extent, quantified the problem. The first, which originated in Canada, is known as "crime prevention through environmental design", CPTED (Jeffery, 1977; Nasar and Upton, 1997); the second, Space Syntax (Hillier and Hanson 1984; Hillier, 2004), started in England. These two lines differ in some of their assumptions and, especially, in the type of analysis proposed, resulting in design measures and urban interventions of a different character. 
The situational theory of crime (Jeffery, 1977) postulates that crimes occur in places that provide the conditions for the criminal act. This may be because, in addition to the natural or social conditions leading to crime, the criminal weighs risk versus reward. These ideas are based on the rational choice theory (Cornish and Clarke, 1986), which proposes the existence of perfectly rational behaviour by the offender; here, the situational-locational factor is a central element of the criminal action. Thus, this theory focuses on the immediate aspects of the criminal event and not just on sociological, psychological or motivational grounds. Likewise, in the context of environmental criminology (Brantingham and Brantingham, 1991) it is postulated that the geographical elements of a crime (i.e. the place) are an essential component of the criminal event and questions relative to "where" take priority over questions about "who".

With these precedents, the CPTED approach links the problem of public safety to public space and the environment, postulating that good design and effective use of the built environment can reduce the perception of fear and the occurrence of crime, especially crimes of opportunity, and attaches great importance to community cohesion. Its original principles, based on the ideas of Jacobs (1961), Newman (1972) and Jeffery (1977), are mainly natural control of access, natural vigilance and territorial reinforcement. Over the years, these principles have been updated to the new forms and standards of living of the population segments on which they focus, incorporating greater citizen participation in the process of urban design. This evolution has placed emphasis on strengthening the identity of the community members and maintaining the community space through local management processes.

The Space Syntax approach (Hillier and Hanson, 1984) suggests a close relationship between urban safety and the movement flows of the city. By favouring the encounter and interaction of different actors in space, security is enhanced, rooted in flow as the best form of control. In this way the concept of virtual community arises, which exists only due to the co-presence of different actors in the same space. Space Syntax also uses the concept of natural vigilance, meaning that the mere existence of the virtual community provides certain levels of security. Consequently, it is considered that the structure of space influences the interaction of people, especially because of its effect on flow patterns (which also depend on attractor elements or land use). Specifically, the method performs a rigorous examination of the spatial characteristics of each configuration under scrutiny (lines of pedestrian or vehicular flow, visual fields, access, etc.) and using digital maps contrasts these with the patterns of spatial location of crime, based on concrete data such as crime and perception of insecurity statistics (Hein, 2004; Hein and Rau, 2004). 
This study looks at these issues, specifically examining the effect of spatial design on the perceived safety of people using streets; these are probably the main urban public spaces, acting as structural elements articulating the movement and encounter of inhabitants. In particular we consider neighbourhood streets in low income sectors associated with social housing projects. In this case, the role of the street is even more relevant, as it is often used as an extension of the dwelling and becomes the main place of interaction for a population where community ties are particularly relevant. From the perspective of social housing beneficiaries, the specific objective of this study is to determine the valuation of certain elements of urban design in the perception of the level of security associated with walking through public spaces in their neighbourhoods.

For this, we designed and implemented a methodology to obtain information directly from the inhabitants, avoiding some of the biases inherent to an opinion poll. We used a stated choice (SC) exercise, well rooted in the areas of interest, and the results were analysed using state-of-the art discrete choice models. In a previous effort (Sillano et al., 2006) we had identified some key attributes that should be included, specifically the presence of people, the type of street and other elements in the public space (such as fences). In the present case, we improved the design of the stated choice experiment and the quality of the images used to present the public spaces studied. Even more importantly, we managed to incorporate a variable associated with cost and this allowed us to compute WTP for improving the various attributes considered.

\section{ATTRIBUTES OF PUBLIC SPACE AND NEIGHBOURHOODS CONSIDERED}

In this section we describe the elements of urban design and public space included in the study, and the main characteristics of the selected sectors representing social housing districts in Santiago.

\subsection{Attributes of public space}

Key attributes relating urban space to safety perceptions are the following: natural vigilance, visual control and maintenance level of the neighbourhood. The main elements that influence each of these aspects were analysed in a previous project (Sillano et al., 2006):

Natural vigilance relates to the protection afforded by the virtual community. The presence and movement of persons, the distribution of access, 
the presence of windows and other points of observation, influence the perceived level of vigilance by those who are or may be in the area.

Visual control relates to the control that pedestrians have on their immediate environment. It is associated with elements such as lighting, amplitude of space, and the presence of visual blocks of different types.

Maintenance level is indirectly related to natural vigilance, as it is associated with the care exercised by those who consider the area as their own. It is also related with visual control as it affects the order and harmony of the environment.

Space Syntax stresses the importance of natural vigilance as a mechanism for controlling space. On the other hand, the CPTED approach stresses the importance of visual control as a key factor on the perception of risk by the population. The maintenance level has been found relevant in several studies related with safety perceptions (Sillano et al., 2006).

\subsection{Study universe}

Social housing neighbourhoods are inhabited by people of low and very low socioeconomic status and have rather high levels of risk and perception of insecurity, both inside the neighbourhood and in its surroundings. Traditionally, these settlements were located on the outskirts of cities, possibly due to the lower value and higher availability of the land to the state.

Our study was conducted for two municipalities in the Santiago periphery, Puente Alto in the south (which has received more social dwellings than any other municipality in Chile since the 90s) and Lo Barnechea, located in the richest northeast of the city. These communities were chosen because both have social housing districts but face very different problems. Puente Alto is one of the municipalities with the most social malaise in the city; in addition, its main social housing sets are located in sectors which are highly segregated from the rest of the city and where there is virtually no urban structure. Lo Barnechea, meanwhile, is a high income municipality and virtually the only one providing for social housing in the richest eastside of Santiago; its social housing units are concentrated in the vicinity of the Mapocho River and its inhabitants share the area with some of the wealthiest groups in the city.

As study universe we chose four neighbourhoods (villas) in the abovementioned sectors. In Puente Alto we considered three villas located in its extreme southwest (Francisco Coloane, El Caleuche and El Volcan). In Lo Barnechea we considered the first stage of La Ermita de San Antonio 
project. The four neighbourhoods are similar in the sense that they are composed of basic Ministry of Housing and Urbanism apartments distributed in three-storey buildings with more than 24 apartments per building, and none is more than fifteen years old. However, they present great differences in design, the funds invested in their construction and maintenance, and the surrounding community.

Francisco Coloane marks the southern boundary of Puente Alto and has about 24 three-storey blocks which house more than a thousand families. The blocks, located around a central courtyard, are mostly close-fenced. The largest public transport roadway is the main street, used as a road axis to the rest of the villas, as it communicates with Santa Rosa Avenue.

El Volcan includes parts of three social housing sets delivered in 1996, which initially grouped around 2,300 families. The storms of 1997 made evident structural problems in the apartments, which led to constant relocation of dwellers. This scenario and other social problems (such as drug trafficking) have resulted in break-ins, vandalism and abandoned apartments. The population suffers from a severe lack of a sense of belonging and little identification with its public space.

El Caleuche consists of pairs of apartment buildings built in line and connected by a staircase, generating a space of co-ownership. The blocks are located in one of two positions along the villa, creating spaces for public use; however, in practice most such areas have become residual spaces (including vacant lots), due to lack of route demarcation, trees or equipment for public use, and also lack of access to the apartments, presenting a high degree of deterioration and vulnerability.

Finally, La Ermita in Lo Barnechea is of more recent construction and its project included landscaping, urban equipment, school and other services. The design of the neighbourhood is more interesting. All apartments face major streets or passages (which intersect at central squares), because each block of buildings conforms a rectangular block, the central area of which corresponds to the backyards of the apartments (private area). Also, the construction resources and on-going space maintenance are far higher than those traditionally invested in social housing projects in Chile. Notwithstanding, the villa is located in a terrain slope on the south side of the Mapocho River, leaving it virtually isolated from the central area of the municipality.

\section{STATED CHOICE EXPERIMENT DESIGN}

To define the values assigned to attributes included in a stated choice (SC) experiment, orthogonal factorial arrangements (usually fractional) were used for several decades. However, this approach is based on techniques 
developed for linear models and is not necessarily appropriate for the highly non-linear discrete choice models we are interested in. Current best practice employs efficient choice designs, typically based on minimizing a measure related with the expected asymptotic covariance matrix (inverse of the Fisher information matrix) of the model of interest, such as D-error (Sándor and Wedel, 2001; Rose and Bliemer, 2009).

Kanninen (2002) proposed an alternative design approach which uses a control variable for optimizing a design structured on the remaining variables. This form is most effective when there is a continuous and manageable variable available. In the case of binary choices, she shows that the minimization problem can be solved in two parts, and works best when the remaining variables take their extreme values and the control variable is set so that the choice probabilities of each alternative at each choice situation are equal to a predetermined value.

In our experiment we asked respondents to choose between pairs of alternatives, as this comparison is more natural for people and it allows an easy process of model formulation to analyse the data. In addition, this format was well received in two previous studies with low-income people in the social housing context (Greene and Ortúzar, 2002; Sillano et al., 2006). In particular, we asked respondents to look at two street images, and choose the one that felt safer. The characteristics of the streets were varied, according to our experimental design, allowing us to detect the influence of the variables of interest. Once people had chosen an image, they were asked to choose again, this time considering that residing in the safest place would imply an associated cost.

\subsection{Variable definition}

A series of focus groups allowed us to understand better what physical variables seemed to be important in the perception of pedestrian insecurity in poor neighbourhoods. Among these was the presence of other people, walking in open rather than confined spaces, the presence of trees, the opacity of fences, etc. We decided to discard street lighting, as it was perceived as too important, by working on the basis of pedestrians moving during day time conditions. As mentioned above, the theory speaks of two composite variables "natural vigilance" and "visual control", which we found to have a clear association with some of the previous physical variables in a preliminary study (Sillano et al., 2006); we also confirmed the relevance of "maintenance level", as had been detected in previous local studies. We selected a series of physical attributes to represent these three concepts and the SC alternatives were presented as pairs of images, among which these attributes changed; selection was done by picking the image where the respondent felt safer. 
Related to natural vigilance (NV) we considered three types of vigilance, each one presented according to the levels observed in the neighbourhoods: (i) potential surveillance, represented by buildings with and without windows, (ii) effective surveillance, represented by the presence or otherwise of other pedestrians in the street, and (iii) stable surveillance which considered the presence (or otherwise) of a corner shop and public transport vehicle (in our case the typical shared taxi that operates these neighbourhoods with fairly fixed routes).

Related to visual control (VC) we included two variables: type of street, which determines visibility along space by comparing a long/straight street vs. a short one leading to a T junction, and presence or absence of fences, ${ }^{1}$ designed to represent some level of visual obstruction.

The maintenance level variable (M) was associated with the general appearance of the street and sidewalks, based on the different types of situations found in practice (i.e. debris, dirt vs. a well-kept lawn, etc.).

Finally, and as the payment mechanism, we included the variable additional mortgage, defined as the difference in monthly payment for the (social) house inhabited by the respondent, which would guarantee that it was located in an area such that walking daily to and from it involved using those streets that felt safer to the respondent. This will be explained further below.

\subsection{Experimental design}

As mentioned above we used a mixed design. We first built an orthogonal factorial design on the basis of differences between the "spatial" variables, considering reasonable combinations of the attributes that represent each one, as follows:

\section{Natural vigilance}

For this variable we considered the three types of surveillance mentioned above, represented by the following differences:

$\Delta \mathrm{NV}_{1}$ : refers to "potential surveillance" and is represented by the difference between an empty street surrounded by the backs of buildings (i.e. no windows or access), as in many parts of the neighbourhoods, and an empty street facing building entrances, and several windows as in main streets and passages.

$\Delta \mathrm{NV}_{2}$ : associated with "effective surveillance", is represented by passing from an empty street facing building entrances, to the same type of street but incorporating pedestrians. 
$\Delta \mathrm{NV}_{3}$ : associated with "stable surveillance", contrasts the same kind of street mentioned above (with pedestrians) with a street featuring a corner shop and a shared taxi, similar to what can be observed in the neighbourhoods.

\section{Visual control}

The physical variables associated with this composite attribute (e.g. type of street and presence of fences) were created with just two levels so they allowed for a single difference each:

$\Delta \mathrm{S}$ : contrasts a short passage ending in a $\mathrm{T}$ junction with a long straight avenue. In our preliminary study we also considered a street that curved, but the T-junction effect (i.e. lack of control due to a possible surprise at the corner) was found to be stronger (Sillano et al., 2006).

$\Delta \mathrm{F}$ : contrasts streets with and without fenced houses. In our preliminary study we tested different types of fencing (more or less opaque), but found the effect confusing as maximum opacity (i.e. concrete fences) led to the idea of walking in back alleys, and semi opaque fences (i.e. with shrubs) led to the idea of well-kept and hence safer areas; for these reasons, here we had just one type of fence, that most regularly found in the neighbourhoods. ${ }^{2}$

\section{Maintenance level}

Our on-site observations led us to determine that the range of variation of this variable should be represented by three levels (good, medium and bad), generating the following differences:

$\Delta \mathrm{M}_{1}$ : contrasts bad and medium maintenance levels; one image presents a street with a damaged road surface and dirty sidewalks, and the other has a good road surface and is clean.

$\Delta \mathrm{M}_{2}$ : contrasts bad and good maintenance levels; in this case "good" adds the presence of well-kept green areas.

The combination of all the above variables led to $128(8 \times 4 \times 4)$ pairs of alternatives, which were presented as eight blocks of 16 treatments each (equally balanced in terms of main effects and first order interactions) to eight sub samples of respondents. Our design was further refined/optimized using additional mortgage as the control variable (Kanninen, 2002); apart from being a very important attribute (i.e. it allows estimation of the WTP associated with the remaining physical 
variables) it was the only continuous variable and thus more easily manageable.

To optimize the design we assumed a MNL model with linear utilities including all the physical variables and the mortgage difference (allowed to vary continuously between Chilean $\$ 2000$ and 6000 , i.e. between US\$3 and 9$)^{3}$. Then, using parameters estimated in our preliminary study plus others obtained at the pilot and pre-test stages, we assigned additional mortgage values to make the choice probabilities as close to 0.5 as possible (we changed the additional mortgage value in units of Chilean $\$ 500$, to make it more realistic). This allowed us to reduce substantially the D-error associated with the design (Rose and Bliemer, 2009).

\subsection{Use of and image design}

Arentze et al. (2003) attempted to explore the potential benefits of adding pictorial information in SC experiments in a South African transport context. They argued that the issue of the influence of presentation modality on choice has arisen because of the problem of cognitive load in SC experiments. They proposed as a potential solution to this problem the use of pictorial information about the attributes, to assist respondents in "constructing and maintaining vivid representations of alternatives in working memory". Their respondents were asked to choose between three labelled transport modes: train, bus and minibus, and one of two blocks of eight choice sets presented to each respondent included pictorial representations of the attributes. The results of their study suggested that the addition of pictorial information did not have a significant impact on either error variance or the measurement of attribute weights.

In our case, as all the information concerning experimental attributes had to be visually represented we decided to use digitally created images, based on photographs of actual streets from the neighbourhoods considered; this made sure that they would not be contaminated by strenuous variables (noise) that could pop up in real photographs (see Figure 9.1). This worked out extremely well as we managed to achieve extremely simple images that allowed the attributes to be clearly perceived.

The use of images has the advantage that respondents confront a graphic representation which looks familiar and resembles their daily environment, reducing the comprehension problems associated with a verbal description of the attributes. This was crucial in our case as we were dealing with respondents having a rather low educational level. The various elements shown in each image were designed independently and combined in successive layers; this way we managed to obtain 

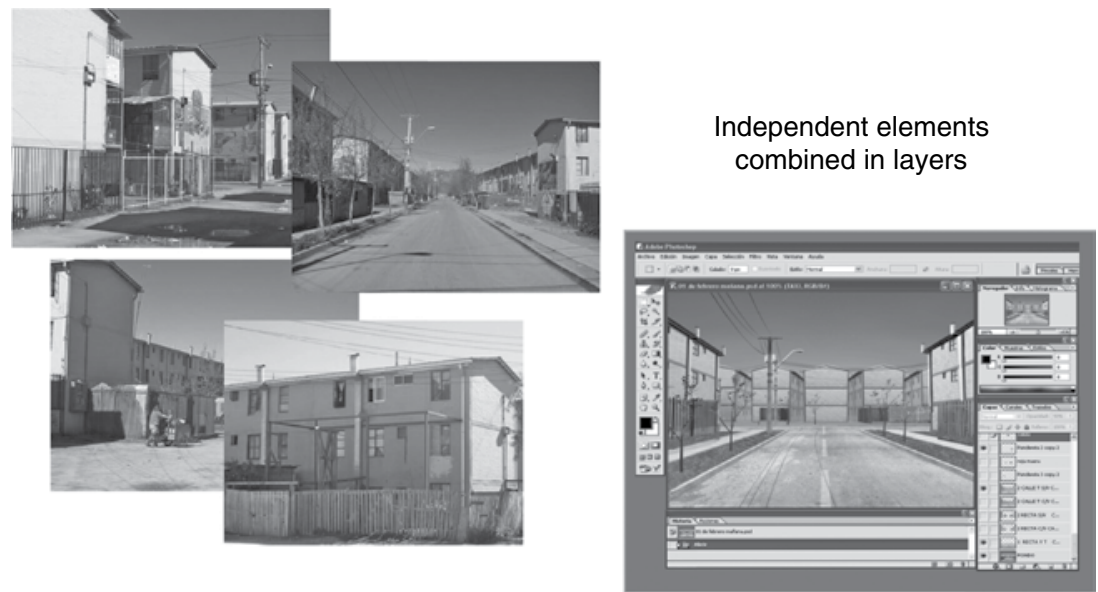

Figure 9.1 Example of image construction
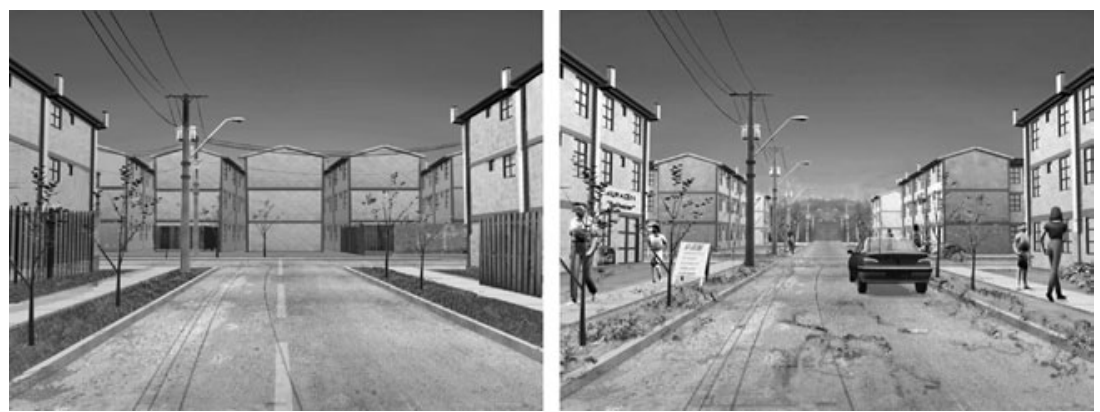

Note: This was not one of the actual pairs presented; it is only shown because it presents the main differences considered in the experiment. The values associated with the physical variables defined above for this pair are: $\Delta \mathrm{NV}_{1}=1 ; \Delta \mathrm{NV}_{2}=1 ; \Delta \mathrm{NV}_{3}=1 ; \Delta \mathrm{M}_{2}=-1 ; \Delta \mathrm{S}$ $=1 ; \Delta \mathrm{F}=-1$.

Figure 9.2: $\quad$ Extreme example of a pair of alternatives

systematically all the required alternatives of the design. Figure 9.2 shows, as an example, extreme differences between a pair of such images.

\subsection{Survey application}

We aimed for and achieved a final sample of 80 respondents in each of the four villas (neighbourhoods) under consideration. Each of the eight blocks, in turn, was applied to 10 people at each villa; this was important 
to maintain the orthogonal properties of the complete design. The survey had two parts: the first sought personal data (sex, age, number and age of children, educational level, family income, and information about perception of safety when walking in the villa) and the second contained the choice game. After the latter was completed, six further questions were asked to confirm consistency in the answers.

The choice game was preceded by a description of the hypothetical context. The dweller's house might be located in different places defined by street images and the relocation of the house implies that "you and your family would need to use the street shown every day when leaving or arriving at your house". For each of the 16 choice situations respondents were asked to make two choices: first, the most secure street (confronting a pair of images), and second, the preferred location for the house, if the street previously chosen included payment of an additional mortgage.

\section{STATISTICAL ANALYSIS OF THE DATA}

\subsection{Socioeconomic characteristics}

For each household we interviewed the head of the household or spouse, most of them young adults (56 per cent from 30 to 40 years old) and mainly women (a third of whom were household heads). A majority of the families had small children (80 per cent with minors and, depending on the villa, between 40 per cent and 64 per cent with children below eight years of age). In Puente Alto, the monthly family income barely surpassed the minimum average legal individual income, and this observed income was about 30 per cent lower than in La Ermita (this relates mainly to the higher rate of stable employees in the latter villa). Regarding educational level, the situation was similar in all villas: less than 40 per cent of respondents did not reach secondary school and among the 47 per cent who did, almost half left it unfinished (only 11 per cent of the population reported some type of high school or technical studies).

\subsection{Consistency and validation of data}

Respondent inconsistency (understood as lack of understanding, or lack of attention) was analysed by looking at the responses to a reduced number of choices that were considered dominant according to the answers given to the control questions. This allowed us to identify 14 individuals who were eliminated from the sample. On the other hand, potentially lexicographic behaviour was identified by marking those individuals 
who systematically chose alternatives on the basis of maximizing (or minimizing) a single attribute. Only the variables level of maintenance and presence of other pedestrians showed relevant amounts of people with this behaviour (depending on the villa, up to 8 per cent and up to 25 per cent of cases, respectively). In both cases, the higher percentage occurred in villas where the back parts of buildings had become abandoned sites.

Regarding cost, individuals who always chose the cheapest alternative were also marked as potentially lexicographic, but only 8 per cent of the sample showed this behaviour. On the other hand, 31 individuals of the highest relative income were left out because in every situation they chose the more expensive alternative and we became convinced that the range of variation used in the survey instrument was inadequate for them. Nonetheless, the 16 treatments in which they responded only to physical attributes were included.

Finally, in this type of experiment the "unable to decide" answers are very informative because they indicate that the alternatives presented had practically the same utility for the respondent, so including this information becomes very relevant in modelling. How to do this is a matter of discussion, but in this case we used these as double answers. In the first one, additional mortgage was assigned to alternative $\mathrm{A}$ and in the second to alternative $\mathrm{B}$; in both cases we assumed the selection of that alternative with the lower cost (this represented less than 9 per cent of all responses). The final sample was obtained after eliminating "inconsistent" individuals, the cost related answers of the 31 individuals mentioned above and by redefining the "unable to decide" answers. On 60 per cent of cases dwellers preferred to select the alternative considered safer, explicitly agreeing to an additional mortgage.

\section{MODELLING RESULTS}

Table 9.1 presents the results of binary MNL and ML models estimated with our data. The utility function is linear in all the variables so the parameters represent utility changes, referred to as safety improvements, in response to the variations described in section 3.2 (costs are in Chilean $\$)$.

The parameters of the visual control variables (type of street and absence of fences) have a sign which is not consistent with our a priori expectations. In the case of the fences, we believe that this was caused by the fact that in most choice situations the images with fences corresponded to a better-kept area. Thus, instead of conveying the feeling that the fence makes it more difficult to assist a pedestrian being mugged, it conveyed the 
Table 9.1 Binary MNL and ML models

\begin{tabular}{lccc}
\hline Attributes & \multicolumn{3}{c}{ Parameters (t test) } \\
\cline { 2 - 4 } & MNL & \multicolumn{2}{c}{$\mathrm{ML}$} \\
\cline { 2 - 4 } & & Mean & Standard deviation \\
\cline { 2 - 4 } Street type $(\Delta \mathrm{S})$ & $-0.111(-3.6)$ & $-0.173(-2.2)$ & $-1.126(-12.4)$ \\
Absence of fences $(\Delta \mathrm{F})$ & $-0.133(-5.9)$ & $-0.294(-5.9)$ & $-0.637(-10.4)$ \\
Maintenance $1\left(\Delta \mathrm{M}_{1}\right)$ & $0.742(22.1)$ & $1.334(14.9)$ & $-1.181(-12.4)$ \\
Maintenance $2\left(\Delta \mathrm{M}_{2}\right)$ & $1.032(28.2)$ & $2.086(19.7)$ & $-1.242(-12.4)$ \\
Presence of windows & $0.432(10.8)$ & $1.056(8.6)$ & $-1.745(-13.7)$ \\
$\quad\left(\Delta \mathrm{NV}_{1}\right)$ & & & \\
Other people $\left(\Delta \mathrm{NV}_{2}\right)$ & $0.283(7.1)$ & $0.824(8.5)$ & $1.208(13.0)$ \\
Corner shop and taxi & $0.093(2.4)$ & $0.222(2.9)$ & $-0.732(-7.5)$ \\
$\quad\left(\Delta \mathrm{NV} \mathrm{V}_{3}\right)$ & & & \\
Additional mortgage & $-0.0002(-21.9)$ & $-0.0006(-11.9)$ & $-0.0009(-18.4)$ \\
$\quad($ cost $)$ & -5650.32 & -3939.35 & \\
$1(\theta)$ &
\end{tabular}

feeling that the area was safer in the sense of having residents who took better care of it. In the case of the T-junction, we suspect that the reason was - once more - a faulty interpretation by respondents (due to lack of care in our design) as the T-junction images were also always associated with a better-kept area.

The rest of the parameters have the expected signs and, as usual, the ML model is significantly better than the MNL model in terms of fit. Also, the standard deviations are in many cases larger than the mean estimates, suggesting a wide variation in tastes among individuals. We do not have space to dwell on these issues further here; the interested reader can consult Iglesias (2007) where we make a fairly complete analysis and also inform about willingness-to-pay estimates from these models and their interpretation.

We also estimated MNL-like models allowing for consistent treatment of the repeated observations by each individual (i.e. the panel effect), and a MNL allowing for systematic taste variations (i.e. to interact the physical attributes with socioeconomic data, see Ortúzar and Willumsen, 2011 p. 279). The latter model allows understanding better the reasons why certain attributes are valued differently by villa, age group, gender and age of the respondent's children. The best model of this type is presented in Table 9.2. ${ }^{4}$

The parameter values are a measure of the relevance of each attribute on the dweller's perception of safety, considering the variations included in 


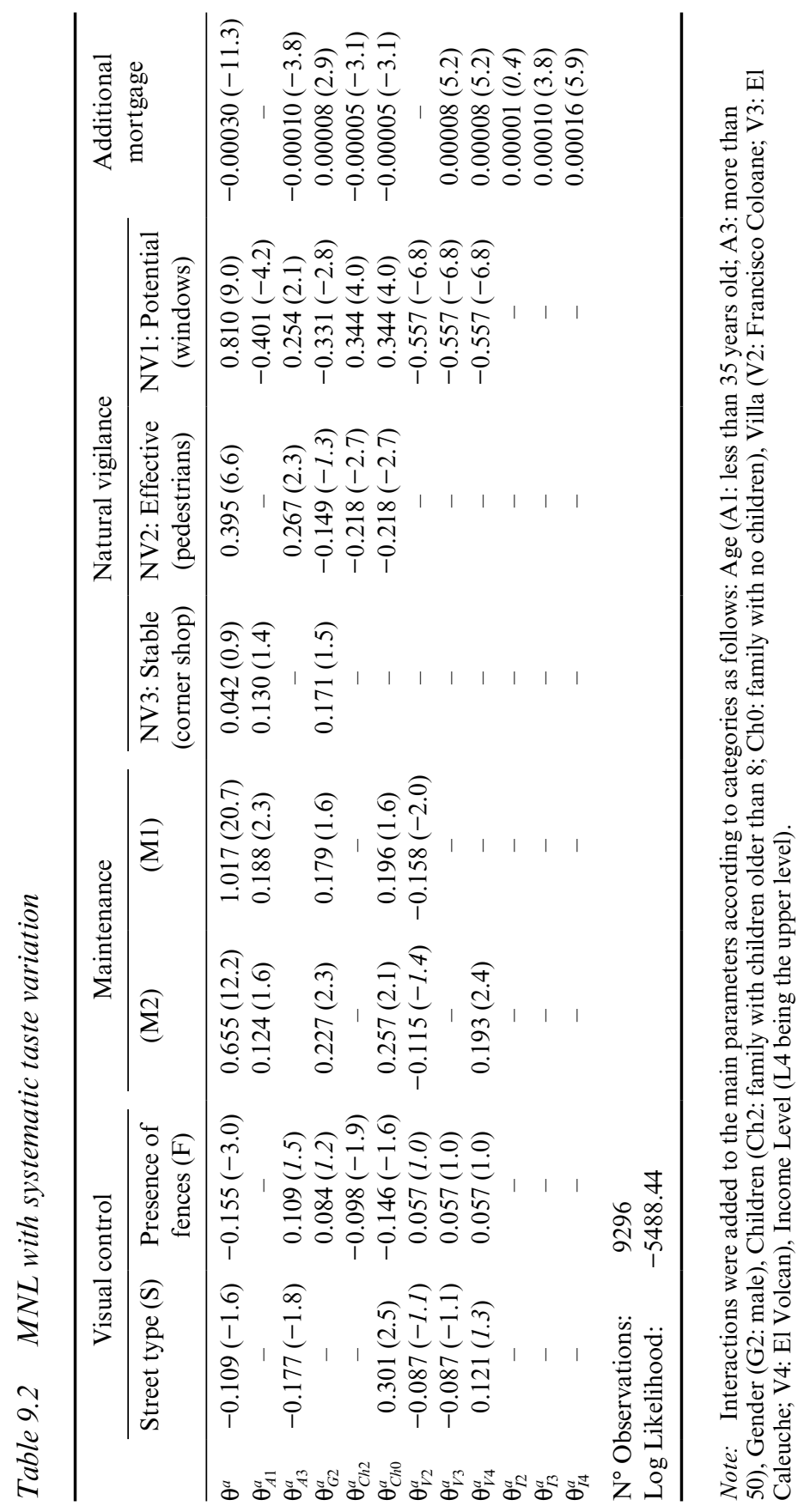


the experiment. For each attribute, socioeconomic effects can be analysed by adding the corresponding additional parameter to the reference value. In general the most relevant socioeconomic characteristics were age, presence of children under eight (and total absence of children) and gender. The dummy Villa results are particularly relevant regarding additional mortgage and presence of windows (as expected from the results of the ML model parameters associated with these attributes). The cost related attribute appears particularly sensitive to age, gender and income level, as expected.

Using the parameter associated with cost (i.e. additional mortgage) it is possible to derive WTP; this measure corresponds to the amount of money that a family would be willing to pay monthly for achieving a benefit in safety as shown in the experiment. The WTP derived from the simple MNL model were: street type: $-\$ 604$; absence of fences: $-\$ 690$; maintenance (M2): \$ 3.860; maintenance (M1) \$5.371; potential surveillance (windows): \$2.247; effective surveillance (pedestrians): \$1.473; stable surveillance (corner shop): $\$ 482$. We will not discuss the values associated with street type and presence of fences for the reasons mentioned above; notwithstanding, it is interesting that the latter had variations in sign depending on age and villa (see Iglesias, 2007).

The model in Table 9.2 in principle allows estimation of WTP for different classes of individuals; however, the study was not designed to estimate a value for each combination that could be considered, as our sample size was not large enough. Notwithstanding, comparing estimated WTP values for different villas and income levels, shows that the WTP follow the expected pattern (increases with income) and the relative importance of each attribute is maintained.

Table 9.3 presents WTP values for the most common segment of men and women (young individuals with children less than 8 and income level 2 ) in the various villas. In general, the WTP values for males are higher than for females; notwithstanding, in the case of presence of windows the WTP for males in the villas in Puente Alto show a contrary sign (in italic in the table; in the focus groups we had observed that young males without children considered this attribute negligible). We attach more credibility to the results for females for three reasons: first, the majority of important family decisions are taken by females in these neighbourhoods; second, when we applied the experiment we were left with the feeling that females took more seriously the budget restriction in the exercise; finally, the proportion of males that we managed to interview was much smaller (close to 25 per cent of the sample only).

It is interesting that the WTP values appear eminently reasonable in the sense that they do not exceed 10 per cent of an average family income, 
Table 9.3 Willingness-to-pay by gender and villa $(\$)$

\begin{tabular}{|c|c|c|c|c|c|c|}
\hline \multirow[t]{3}{*}{ Gender } & \multirow[t]{3}{*}{ Villa } & \multicolumn{5}{|c|}{ Attribute } \\
\hline & & \multicolumn{2}{|c|}{ Maintenance } & \multicolumn{3}{|c|}{ Natural Vigilance } \\
\hline & & M1 & M2 & $\mathrm{NV}_{1}$ & $\mathrm{NV}_{2}$ & $\mathrm{NV}_{3}$ \\
\hline \multirow[t]{4}{*}{ Women } & El Volcan & 4937 & 4119 & 1228 & 1918 & 202 \\
\hline & El Caleuche & 4937 & 3180 & 1228 & 1918 & 202 \\
\hline & Fco. Coloane & 2975 & 1872 & 876 & 1369 & 144 \\
\hline & La Ermita & 3524 & 2270 & 2807 & 1369 & 144 \\
\hline \multirow[t]{4}{*}{ Men } & El Volcan & 9213 & 8286 & -602 & 1899 & 1635 \\
\hline & El Caleuche & 9213 & 6796 & -602 & 1899 & 1635 \\
\hline & Fco. Coloane & 4885 & 3612 & -368 & 1161 & 999 \\
\hline & La Ermita & 5631 & 4153 & 2255 & 1161 & 999 \\
\hline
\end{tabular}

whilst being non-negligible. This corroborates that the attributes studied are relevant to the population when considering their feeling of safety.

\section{CONCLUSIONS}

We studied the importance of public space characteristics in the perception of safety of inhabitants from low income neighbourhoods. Street maintenance and natural vigilance (both potential and effective surveillance) were the most relevant aspects. A model allowing for systematic taste variations revealed strong differences in perception for different types of dweller (mainly between individuals of different gender, age, family structure and income). The use of digitally designed pictures to represent alternatives was crucial, in particular given the low educational level of most participants. The only non-visual attribute was a cost related variable that was incorporated through a payment mechanism that was familiar to the inhabitants (i.e. additional mortgage for living in a safer area). At the experimental design stage this variable was used as a control variable (to adjust design efficiency), and its presence allowed for the estimation of reasonable WTP values that may be compared with the cost of measures that might bring in changes similar to those studied here.

Regarding the use of images, we detected problems in the case of attributes that represented non-direct effects such as those related to visual control of space. This is expected when the attribute can be associated with more than one "meaning" to the respondent (i.e. a fence covered with shrubbery can both impede visual control from inside dwellings - a bad 
thing; but also imply an area where people take care of their houses and surroundings - a good thing). Thus, it is important to detect these problems at the design stage (focus groups, pilot applications). If such dual effects cannot be prevented they should be explicitly incorporated in order to treat the effects properly at the modelling stage.

\section{ACKNOWLEDGEMENTS}

We are grateful to FONDECYT (Project 1050672), the Millennium Institute in Complex Engineering Systems (Projects P05-004-F and Basal FBO-16), the Alexander von Humboldt Foundation and the TEMPO Project (Research Council of Norway) for having supported our research. We are also very grateful for the insightful comments of an anonymous referee.

\section{NOTES}

1. In a previous study we tested if the opacity of fences (i.e. concrete, covered with shrubs or completely see-through) influenced the perception of safety, finding that it was difficult to disentangle this effect from others such as that a fence covered with shrubs looks prettier and better kept and, hence, less threatening.

2. We left out the presence or absence of trees as it was also confounded with better maintenance rather than with the dangerous possibility of keeping criminals out of sight, as the CPTED approach postulates.

3. The range for this additional mortgage was determined according to the willingness to pay values reported by focus group participants.

4. Some less significant variables were kept in as they were considered relevant and present a relatively high value (compared to the reference parameter), and eliminating them resulted in a non-negligible loss of log-likelihood (the t-ratios of these parameters are in italic). For additional mortgage the parameter associated with the second level of income (I2) was kept in spite of its low significance, because it showed the expected behaviour (the three parameters associated with income level are positive and increase with income, so the value falls with income and stays negative.

\section{REFERENCES}

Arentze, T., Borgers, A., Timmermans, H. and Del Mistro, R. (2003), Transport stated choice responses: effects of task complexity, presentation format and literacy, Transportation Research, 39E(3), 229-244.

Brantingham, P.J. and Brantingham, P.L. (1991), Environmental Criminology, Prospect Heights, IL: Waveland.

Cornish, D. and Clarke, R.V. (1986), The Reasoning Criminal, New York: Springer-Verlag. 
Greene, M. and Ortúzar, J. de D. (2002), Willingness-to-pay for social housing attributes: a case study from Chile, International Planning Studies, 7(1), 151-158.

Hein, A. (2004), La georeferenciación como herramienta para el diagnóstico de problemas de seguridad ciudadana en el ámbito local, Santiago: Fundación Paz Ciudadana (in Spanish).

Hein, A. and Rau, M. (2004), Método de diagnóstico espacial de problemas delictivos: análisis de un caso, Santiago: Fundación Paz Ciudadana (in Spanish).

Hillier, B. (2004), Can streets be made safe?, Urban Design International, 9(1), $31-45$.

Hillier, B. and Hanson, J. (1984), The Social Logic of Space, Cambridge: Cambridge University Press.

Iglesias, P. (2007), Valoración de Atributos de Diseño Urbano en la Percepción de Seguridad Ciudadana en Barrios de Bajo Ingreso, M.Sc. Thesis, Pontificia Universidad Católica de Chile (in Spanish).

Jacobs, J. (1961), The Death and Life of Great American Cities, New York: Random House.

Jeffery, C.R. (1977), Crime Prevention through Environmental Design, Beverly Hills: Sage.

Kanninen, B. (2002), Optimal design for multinomial choice experiments, Journal of Marketing Research, 39(2), 214-227.

Nasar, J.L. and Upton, K. (1997), Landscapes of fear and stress, Environment and Behaviour, 29(3), 291-323.

Newman, O. (1972), Defensible Space: Crime Prevention through Urban Design, New York: Collier.

Ortúzar, J. de D. and Willumsen, L.G. (2011), Modelling Transport, 4th Edition, Chichester: John Wiley and Sons.

Paz Ciudadana (2003), Espacios urbanos seguros: recomendaciones de diseño y gestión comunitaria para la obtención de espacios urbanos seguros, Santiago: Fundación Paz Ciudadana for Ministerio del Interior and Ministerio de Vivienda y Urbanismo (in Spanish).

Rose, J.M. and Bliemer, M.C.J. (2009), Constructing efficient stated choice experimental designs, Transport Reviews, 29(5), 587-617.

Sándor, Z. and Wedel, M. (2001), Designing conjoint choice experiments using managers' prior beliefs, Journal of Marketing Research, 38(4), 430-444.

Sillano, M., Greene, M. and Ortúzar, J. de D. (2006), Percepción de seguridad en barrios de escasos recursos, EURE, 32(1), 17-35 (in Spanish). 